\title{
Tumbre: Análisis del material lítico
}

Frank Pereyea ${ }^{1}$

\section{Tumbre 2}

Novecientos cuarenta y cinco artefactos de piedra han sido recolectados en Tumbre 2 en las dos expediciones de octubre y noviembre 1976. Estos artefactos pueden dividirse en cuatro categorías:

1. Desechos $(D)$ : Fragmentos de lascas o láminas con menos de $2 \mathrm{~cm}$.

2. Lascas sin retoque: Lascas, láminas o fragmentos de éstos sin retoque.

3. Lascas con retoque: Lascas, láminas o fragmentos de éstos que tienen retoque en los bordes.
4. Núcleos: Pedazos de materia prima de los cuales se sacaron lascas o láminas con retoque o sin retoque.

La división general de los artefactos encontrados es la siguiente: 473 desechos; 250 lascas/láminas sin retoque; 211 lascas/láminas con retoques; 10 núcleos; subtotal 944 más una piedra incisa (TUM 2-173).

La distribución de las categorías en la superficie según cuadrículas, no indica ningún detalle de importancia.

\begin{tabular}{|c|c|c|c|c|c|c|}
\hline Area & Artefactos & D & LSR & $\mathbf{N}$ & $\mathbf{N}$ & Total \\
\hline 1. Colección Intensiva (octubre 6 de 1976) & & & & & & \\
\hline NE Cuad. & $34-36$ & 12 & 0 & 1 & 0 & 13 \\
\hline SE Cuad. & $15-33$ & 16 & 3 & 0 & 0 & 19 \\
\hline NO Cuad. & $47-61$ & 12 & 3 & 0 & 0 & 15 \\
\hline SO Cuad. & $62-67$ & 6 & 0 & 0 & 0 & 6 \\
\hline 2. Sondeo (octubre 6 de 1976) & $1-14$ & 9 & 5 & 0 & 0 & 14 \\
\hline 3. Colección general (octubre 5 de 1976) & $128-161$ & 2 & 11 & 21 & 0 & 34 \\
\hline 4. Colección general (octubre 6 de 1976) & $68-127-162-172$ & 18 & 30 & 18 & 5 & 71 \\
\hline 5. Zona I & $240-246$ & 2 & 10 & 7 & 0 & 19 \\
\hline 6. Zona II & $227-239$ & 48 & 15 & 13 & 0 & 76 \\
\hline 7. Zona III & $325-342$ & 37 & 23 & 18 & 0 & 78 \\
\hline 8. Zona IV & 247-292 & 108 & 54 & 46 & 0 & 208 \\
\hline 9. Zona V & 293-298 & 3 & 5 & 6 & 3 & 17 \\
\hline 10. Zona VI & $290-324$ & 57 & 30 & 26 & 0 & 113 \\
\hline 11. Cuad. $4 \mathrm{~N}-9 \mathrm{O}$ & & - & - & - & - & 0 \\
\hline 12. Cuad. $3 \mathrm{~N}-3 \mathrm{O}$ & & 9 & 0 & 0 & 0 & 9 \\
\hline 13. Cuad. $3 \mathrm{~N}-7 \mathrm{O}$ & & - & - & - & - & 0 \\
\hline 14. Cuad. $3 \mathrm{~N}-8 \mathrm{O}$ & & - & - & - & - & 0 \\
\hline 15. Cuad. $3 \mathrm{~N}-9 \mathrm{O}$ & & - & - & - & - & 0 \\
\hline 16. Cuad. $3 \mathrm{~N}-10 \mathrm{O}$ & & - & - & - & - & 0 \\
\hline 17. Cuad. $3 \mathrm{~N}-11 \mathrm{O}$ & 217 & 0 & 0 & 1 & 0 & 1 \\
\hline 18. Cuad. $3 \mathrm{~N}-12 \mathrm{O}$ & & - & - & & & 0 \\
\hline 19. Cuad. $2 \mathrm{~N}-3 \mathrm{O}$ & 187 & 16 & 4 & 1 & 0 & 21 \\
\hline 20. Cuad. $2 \mathrm{~N}-8 \mathrm{O}$ & & - & - & - & - & - \\
\hline 21. Cuad. $2 \mathrm{~N}-9 \mathrm{O}$ & & - & - & - & - & 0 \\
\hline 22. Cuad. $2 \mathrm{~N}-10 \mathrm{O}$ & & 1 & 0 & 0 & 0 & 1 \\
\hline 23. Cuad. $1 \mathrm{~N}-0 \mathrm{O}$ & & 1 & 0 & 0 & 0 & 1 \\
\hline 24. Cuad. $1 \mathrm{~N}-3 \mathrm{O}$ & 196-204 & 18 & 6 & 9 & 0 & 33 \\
\hline
\end{tabular}

\footnotetext{
${ }^{1}$ Universidad de Michigan, ESTADOS UNIDOS.
} 


\begin{tabular}{|c|c|c|c|c|c|c|}
\hline Area & Artefactos & D & LSR & LCR & $\mathbf{N}$ & Total \\
\hline 25. Cuad. $1 \mathrm{~N}-4 \mathrm{O}$ & 214-216 & 9 & 4 & 3 & 0 & 16 \\
\hline 26. Cuad. $1 \mathrm{~N} .8 \mathrm{O}$ & & - & - & - & - & 0 \\
\hline 27. Cuad. 1 N.9O & & - & - & - & - & 0 \\
\hline 28. Cuad. $1 \mathrm{~N} .10 \mathrm{O}$ & 190 & 0 & 1 & 1 & 1 & 3 \\
\hline 29. Cuad. ON.IE & & 0 & 1 & 0 & 0 & 1 \\
\hline 30. Cuad. ON-OO & 178 & 0 & 1 & 1 & 0 & 2 \\
\hline 31. Cuad. ON.1O & & 0 & 2 & 0 & 0 & 2 \\
\hline 32. Cuad. ON-2O & $179-182$ & 2 & 3 & 4 & 0 & 9 \\
\hline 33. Cuad. ON-3O & 205-207 & 11 & 6 & 3 & 0 & 20 \\
\hline 34. Cuad. ON-4O & $218-226$ & 19 & 6 & 9 & 1 & 35 \\
\hline 35. Cuad. ON-5O & 208 & 4 & 3 & 1 & 0 & 8 \\
\hline 36. Cuad. ON-9O & 209 & 2 & 1 & 1 & 0 & 4 \\
\hline 37. Cuad. 1S-2O & 195 & 5 & 0 & 1 & 0 & 6 \\
\hline 38. Cuad. $13-30$ & 191-194, 344 & 9 & 4 & 5 & 0 & 18 \\
\hline 39. Cuad. $1 \mathrm{~S}-4 \mathrm{O}$ & $183-186$ & 20 & 9 & 4 & 0 & 33 \\
\hline 40. Cuad. IS-5O & $212-213$ & 9 & 3 & 2 & 0 & 14 \\
\hline 41. Cuad. IS.6O & & 1 & 1 & 0 & 0 & 2 \\
\hline 42. Cuad. 1 S.9O & & 0 & 1 & 0 & 0 & 1 \\
\hline 43. Cuad. $25-2 \mathrm{O}$ & 343 & 1 & 1 & 1 & 0 & 3 \\
\hline 44. Cuad. 2S.3O & 210 & 2 & 0 & 1 & 0 & 3 \\
\hline 45. Cuad. $2 \mathrm{~S}-4 \mathrm{O}$ & 174-177 & 2 & 1 & 4 & 0 & 7 \\
\hline 46. Cuad. 2S-5O & & 2 & 2 & 0 & 0 & 4 \\
\hline 47. Cuad. 3S-3O & & - & - & - & - & 0 \\
\hline 48. Cuad. 4S-3O & & - & - & - & - & 0 \\
\hline \multicolumn{7}{|l|}{ 49. Artefactos aislados: } \\
\hline Area 100 & & - & 1 & - & - & 1 \\
\hline Area 101 & 211 & - & - & 1 & - & 1 \\
\hline Area 102 & 188-189 & - & - & 2 & - & 2 \\
\hline \multicolumn{2}{|l|}{ Total } & 473 & 250 & 211 & 10 & 944 \\
\hline
\end{tabular}

Cuadro 1. Artefactos líticos de Tumbre 2.

Los instrumentos que se pueden clasificar son dos: puntas y raspadores. Las puntas han sido consideradas siempre en las clasificaciones anteriores como el tipo diagnóstico de una industria. Las puntas de Tumbre 2 han sido clasificadas según un sistema que elaboramos para futuras clasificaciones de las industrias líticas de San Pedro de Atacama -el cual esperamos publicar pronto-, concluyéndose:

1. La materia prima de las puntas es $58 \%$ de sílice, $30 \%$ de basalto, $11 \%$ de criptocristallina cuarzo.

2. Sólo las puntas de basalto y cuarzo criptocistallina tienen muesca y aletas.

3. Las bases preferenciales de sílice forman dos clases:
a) punta redonda (21)
b) irregular (19).

4. Las bases para puntas sobre basalto son tres:
a) redonda apuntada (5)
b) irregular (6)
c) incurvada (7).

5. Cuatro puntas tienen acanaladura.

6. Todas las puntas tienen pátina.

7. Las puntas enteras poseen una proporción entre largo y ancho de $2: 1$ y $3: 1$.

Las puntas de Tumbre 2 se pueden clasificar en 5 clases:

1. Puntas de basalto con bases curvas, aletas redondas y lengua convergente. Estas y aquellas del $\mathrm{n}^{\mathrm{o}} 2$ son idénticas al tipo 3 de Tambillo descrito por Kaltwasser (1963:136) (artefactos 139, 233, 265). 
2. Puntas basálticas con bases encurvadas, aletas pequeñas apuntadas, bordes cerrados y una lengua derecha convergente (artefactos 108, 250, 284).

3. La clase predominante de puntas es de material variable, pero todos tienen una punta redonda convergente, filos encurvados y bases redondas o apuntadas (p.e., artefactos 107, 112, 175, 176, 191, 2290). Corresponden al tipo 6 de Tambillo (Kaltwasser 1963:137).

4. Aparece una sola punta de criptocristallina de cuarzo, tiene aletas redondas y lengua con sus lados paralelos y una base redonda: Esta punta está quebrada desde las aletas para arriba (artefacto 134).

5. Otra punta única de cuarzo criptocristallina tiene las aletas redondas, pero con una lengua convergente con base irregular (artefacto 133).

Una pequeña clase de cuatro raspadores bien hechos, se encuentra en Tumbre 2 :

Artefacto 95: Obsidiana, semicircular con una cara lisa; con pátina; $2.2 \times 2.8 \times 0.9 \mathrm{~cm}$.

Artefacto 232: Obsidiana, oval con un lado quebrado; todos los otros lados tienen retoque; con pátina; 2.3 x $2.2 \times 0.8 \mathrm{~cm}$.

Artefacto 285: Chert (?), todos los lados tienen retoque abrupto; fuertemente patinada; $2.3 \times 2.2$ $\mathrm{x} 0.8 \mathrm{~cm}$.

Artefacto 318: Obsidiana en forma oblonga; retoque abrupto en un solo lado; retoque irregular en los otros lados; pátina; $2.0 \times 1.6$ x $0.8 \mathrm{~cm}$. Otro artefacto distinto se encuentra en Tumbre 2.

Artefacto 251: Basalto, de forma oblonga con un lado dentado con retoque; puede ser un serrucho; $4.3 \times 1.8 \times 0.7 \mathrm{~cm}$.

\section{Conclusiones}

1. El análisis de los artefactos indica que son morfológicamente de la industria tambilliense ${ }^{2}$.

2. Las pircas y la poca cantidad de varios tipos de artefactos, contrasta con otros sitios señalados como bases (Serracino 1976), y la falta de estratigrafía indica claramente que en este piso ecológico de altura existen sólo a cortos períodos de permanencia y, por lo tanto, se justificaría la denominación de sitios estacionales.

3. La diferencia entre Tumbre 1 y Tumbre 2 en cuanto a estructuras de pircas se refiere y tipos de materiales encontrados (p.e., raspadores en Tumbre 2 y su ausencia en Tumbre 1, huesos en Tumbre 2 y su ausencia en Tumbre 1), indican que la funcionalidad de Tumbre 1 es diferente de la de Tumbre 2. El primero se utilizaba para dormir, mientras que el segundo para carnear los animales.

Estas conclusiones tendrán claridad lógica una vez que publiquemos el trabajo sobre un sitio base, el cual ya hemos comenzado en Calarcoco, que posee una cantidad mayor de herramientas y artefactos, diferentes tipos de pircas, con estratigrafía y un cementerio. Pensemos que la tipología de material, sin embargo, no cambiará. La analogía de esta quebrada con otras en la misma área indicaría patrones similares entre ellas. Consideramos que el modelo propuesto en 1976 es válido y corresponde a la realidad.

P.S.: Desde Calarcoco, sitio base, tenemos ahora tres fechas radiocarbónicas que dan 3170 AC cuyo detalle será prontamente publicado.

Este concepto corresponde a evidencias de superficie agrupadas con criterio tipológico según las propuestas de Le Paige. Las excavaciones estratigráficas en Tambillo y otros campamentos a cargo de L. Núñez, señalan la presencia de otros componentes tipológicos esta vez con asociados orgánicos (carbón) datados radiocarbónicamente. 